Int. J. Dev. Biol. 50: 543-552 (2006)

doi: $10.1387 / \mathrm{ijdb} .052122 \mathrm{ok}$

Original Article

\title{
The dual role of chorion peroxidase in Bactrocera oleae chorion assembly
}

\author{
OURANIA A. KONSTANDI ${ }^{1}$, ISSIDORA S. PAPASSIDERI*,1, DIMITRIOS J. STRAVOPODIS ${ }^{1}$, MARIANNA H. \\ ANTONELOU ${ }^{1}$, CHRISTOS A. KENOUTIS², DESPINA C. STEFANIDOU ${ }^{1}$ and LUKAS H. MARGARITIS ${ }^{1}$ \\ ${ }^{1}$ Department of Cell Biology and Biophysics, Faculty of Biology, University of Athens, Athens, Greece and ${ }^{2}$ Institute of Biology, National \\ Center for Scientific Research (NCSR) "Demokritos", Athens, Greece
}

\begin{abstract}
In the present study, we reveal for the first time that the Bactrocera oleae chorion peroxidase (bPxd) participates essentially in $B$. oleae chorion formation and clearly represents the homologous member of Drosophila melanogaster chorion peroxidase (Pxd). Comparative sequence analysis disclosed that the bPxdcDNA semi-central region, which encodes for the putative catalytic domain of the enzyme, exhibits great homology $(98 \%)$ with its Pxd counterpart. Thus, it is very likely that bPxd is highly responsible for the chorion hardening process, through protein cross-linking mediated by the formation of di- and tri-tyrosine bonds. Distinct molecular weight bPxd RNA transcripts were detected in Northern blotting analysis of total RNA extracts of adult flies $(2.9$ and $1.7 \mathrm{~kb})$ and ovaries $(2.2 \mathrm{~kb})$. The ovarian-specific $b P x d$ RNA transcript is selectively expressed in the follicle cell layer during the late stages of oogenesis 12-14, as revealed by in situ hybridization. Moreover, reverse transcription reactions confirmed the stage-specific developmental regulation of the $b P x d$ gene, which is maximally expressed during stage 13 . Western blotting with the rabbit anti-rAePO polyclonal antibody revealed three immunoreactive bands of 76, 66 and $54 \mathrm{kDa}$ in crude protein extracts from adult flies, while in larva and purified chorion preparations, a unique $54 \mathrm{kDa}$ band was clearly detected. Immunolocalization experiments revealed that bPxd peroxidase constitutes an essential structural chorionic component, being abundantly localized in all the successive chorionic layers and vitelline membrane as well.
\end{abstract}

KEY WORDS: Bactrocera oleae, bPxd, chorion, oogenesis, peroxidase

\section{Introduction}

The egg of the olive fly, Bactrocera oleae(Diptera, Tephritidae), is laid inside olives and the larva eventually destroys the fruit. The oocyte is enveloped by several distinct layers, which are produced during the late stages of oogenesis, named choriogenesis. The assembly process of a physiologically developed eggshell, or chorion, in $B$. oleaeprovides an excellent in vivomodel system to thoroughly describe the fundamental molecular mechanisms governing various complicated networks of protein-protein specific interactions and intercalation events mainly characterized by the infiltration and interjection of tardily synthesized proteins into precociously preformed scaffolds (Trougakos and Margaritis, 1998a).

The chorion, a "sophisticated" complex structure that surrounds the main body of the egg outside of the thick vitelline membrane, includes a "wax" layer, an innermost chorionic layer (ICL), an endochorion consisting of inner and outer layers interconnected with pillars and cavities similar to their counterparts in
Drosophila melanogaster, as well as inner and outer exochorionic layers (Margaritis, 1985b). Its anterior pole region is shaped like an inverted cup, which is mainly described as a hollow structure around its base, containing very large openings directly communicating with the environment. Holes through the surface of the endochorion result from the deposition of endochorionic material around follicular cell microvilli (Mouzaki and Margaritis, 1991a). The whole biological process of chorion formation has been divided into nine [11-14 (11A, 11B, 12A, 12B, 12C, 13A, 13B, 14A and $14 \mathrm{~B})$ ] successive stages and is activated during the late stages of oogenesis (choriogenesis), involving intense synthetic and secretory activities of the follicular cell layer (Margaritis, 1986; Mouzaki and Margaritis, 1991a; Margaritis and Mazzini, 1998).

All the consecutive chorionic layers are mostly composed by

Abbreviations used in this paper: bPxd, Bactrocera oleae chorion peroxidase; Pxd Drosophila chorion peroxidase; ICL, innermost chorionic layer; LM, light microscopy; TEM, transmission electron microscopy.

\footnotetext{
*Address correspondence to: Dr. Issidora S. Papassideri. Department of Cell Biology and Biophysics, Faculty of Biology, University of Athens, Panepistimiopolis, 15784, Athens, Greece. Tel: +30-210-727-4546. Fax: +30-210-727-4742. e-mail: ipapasid@biol.uoa.gr
} 
proteinaceous components (Regier and Kafatos, 1985), except from the fibrous exochorion, which mainly contains polysaccharides. Chorion proteins are deposited in sequential distinct groups in overlapping layers, according to an accurate developmental program of the follicular epithelium, which is exclusively responsible for the formation of the chorion structure. The six major chorion proteins of $D$. melanogaster are classified in three discrete subgroups as "early" (S36, S38), "middle" (S16, S19) and "late" (S15, S18), according to the egg chamber developmental stage they are selectively produced and secreted. The chorion genes of the major structural proteins are highly conserved among all Diptera species, studied so far (Vlachou et al., 1997) and they comprise a representative and elegant example of differentially amplified gene clusters, being asynchronously regulated in the various follicle cell subpopulations (Parks and Spradling, 1987; Trougakos and Margaritis, 1998b).

Following the complicated protein-protein interactions and intercalation events occurring during the chorion formation process, the final step in producing a functional and completely assembled chorion is the insolubilization, or hardening, reaction,

A

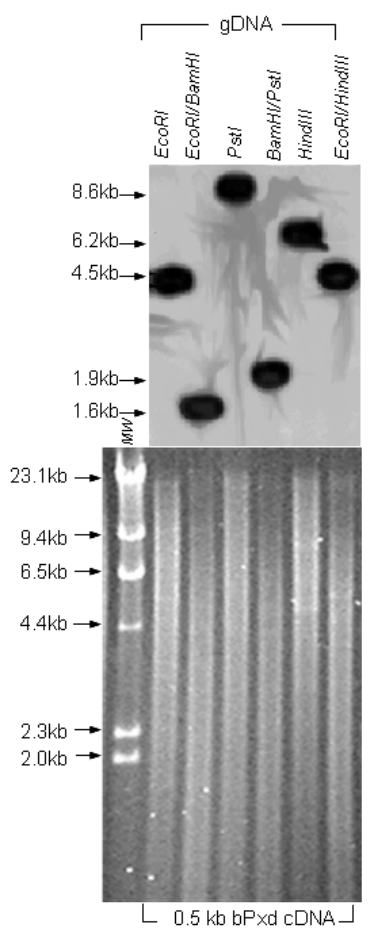

B

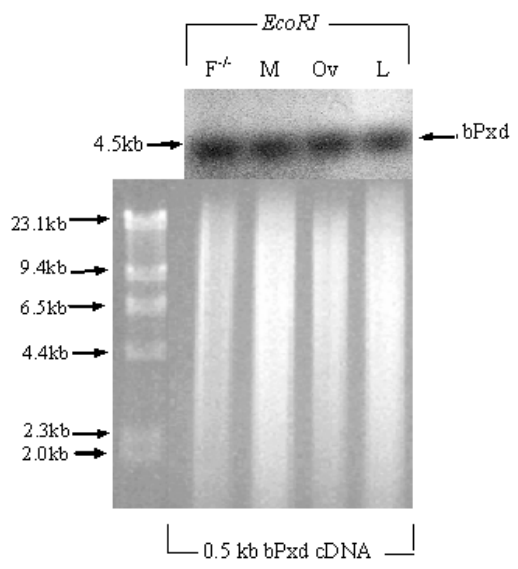

Fig. 1. The bPxd genetic locus represents a single copy gene, which is not differentially amplified. (A) The $0.5 \mathrm{~kb}$ bPxd cDNA fragment was purified and used for high stringency Southern blotting of $\mathrm{B}$. oleae genomic DNA (gDNA) isolated from adult flies (females without ovaries and males) and subsequently digested with the EcoRI, BamHI, Pstl and Hindlll restriction endonucleases (single or double incuba-

tions). An unchallengeable restriction profile of a single copy gene was observed. (B) B. oleae gDNA preparations, isolated from adult female flies without ovaries $\left(\mathrm{F}^{--}-\right)$, adult male flies $(\mathrm{M})$, ovaries $(\mathrm{OV})$ and larvae $(\mathrm{L})$, were digested with the restriction endonuclease EcoRI and subsequently separated by agarose gel electrophoresis. After transfer, the blot was hybridized, under high stringency conditions, using as probe the 0.5 $k b$ bPxd $c D N A$ fragment. The similarities among all the positive signals obtained (4.5 kb EcoRI genomic fragments), in all the analyzed DNA preparations ( $F^{--}, M, O v$ and $\left.L\right)$, strongly indicate the absence of any amplification event in the bPxd genetic locus. The upper part of $(A, B)$ shows a developed autoradiograph, while the bottom part illustrates the ethidium bromide-stained agarose gel before transfer. which, in Drosophila, is mainly catalyzed through a chorion peroxidase-mediated di- and tri-tyrosine bonds generation among the major and likely the minor, chorion proteins. Strong peroxidase activity has been histochemically detected in the chorion of Drosophila (Mindrinos et al., 1980; Trougakos and Margaritis, 2002), as well as in the chorion of Ceratitis capitata, B. oleae (Margaritis, 1985b; Mouzaki and Margaritis, 1991b) and Eurytoma amygdali (Mouzaki and Margaritis, 1994). The function of the enzyme is upregulated, during the last stage of oogenesis (stage 14), by the presence of endogenously synthesized and released hydrogen peroxide $\left(\mathrm{H}_{2} \mathrm{O}_{2}\right)$ molecules. When Diptera species were treated in vivo with the, widely used, peroxidase inhibitor phloroglucinol there was a complete inhibition of the chorion peroxidase activity detected, tightly accompanied with the production of non-matured and finally non-survived eggs, in all the affected insects (Keramaris et al., 1996).

Due to the significant economic damage caused by the olive fly in the agricultural crop production, a number of genetically modifying methods have been developed in order to encounter and control this calamitous situation. The primary initiative and basically one of the most representative and fundamental approaches, is the sterile insect technique (SIT), which is defined as the sterilization by irradiation protocol (Anwar et al., 1971). The prospects for improving the SIT technology, through the construction of genetically modified stable strains, permitting the release of only male sterile flies (Louis et al., 1987), have been significantly enhanced by the revolutionary development of a powerful and efficient transformation system for $C$. capitata (Loukeris et al., 1995).

In the present study, we demonstrate that the $B$. oleaechorion peroxidase, bPxd, a highly homologous member with the Drosophila Pxd peroxidase (Konstandi et al., 2005), plays an essential role and participates with a dual fashion in the chorion assembly and formation process. The totality of our conclusions derived from (a) Southern blotting, (b) Northern blotting, (c) semi-quantitative RT-PCR reactions, (d) in situ hybridization analysis, (e) Western blotting and (f) immunolocalization approaches (Light Microscopy immunodetection and Transmission Electron Microscopy immunogold labelling), compared with previously reported data concerning the DrosophilaPxd peroxidase (Konstandi et al., 2005), strongly suggest for the presence of a highly conserved mechanism of chorion hardening process among all Diptera. Thus, by exploiting the diverse and especially the genetically developed, technologies for pest control, the $B$. oleae chorion peroxidase, bPxd, could comprise a crucial protein to be directly targeted in vivo, in order to develop highly successful protocols for a large variety of agricultural applications.

\section{Results}

\section{Strong phylogenetic conservation of bPxd cDNA}

Two specific primers were designed, the forward pQUE and the reverse pQUErev, according to sequences corresponding to conserved regions among insect and mammalian peroxidase genes (Konstandi et al., 2005). A 0.5 kb cDNA fragment was amplified through a reverse transcription-PCR (RT-PCR) approach, using as a template the total RNA preparation purified from dissected $B$. oleae ovaries and subsequently cloned into the pGEM-T-easy vector, according to manufacturer's instructions. 
Comparative analysis of the DNA sequencing data revealed an identity of $98 \%$ with the Drosophila Pxd cDNA clone, previously isolated by Konstandi et al. (2005), exhibiting only two "silent" nucleotide differences (without any impact on the amino acid sequence of the protein) and also showing significant homologies with the mammalian myeloperoxidase (MPO), thyroid peroxidase (TPO) and eosinophil peroxidase (EOS) (data not shown). The cloned $0.5 \mathrm{~kb}$ bPxd cDNA fragment likely corresponds to the catalytic domain (CD) of the $B$. oleaeputative peroxidase and thus was selected as the most suitable probe for all hybridization experiments.

\section{The gene amplification rule does not apply for the single copy gene bPxd}

Similarly to what has been previously reported for $D$. melanogaster (Konstandi et al., 2005), a single copy homologous gene (bPxd) is presented to occur in the $B$. oleaegenome, according to the Southern blotting analysis of genomic DNA (Sambrook et al., 1989) purified from adult flies, subsequently digested with different restriction endonucleases (ECORI, BamHI, Pst/ and HindIII) and finally, after band-separation and blotting, hybridized against the $0.5 \mathrm{~kb}$ RT-PCR fragment directly generated from total RNA extracts of dissected ovaries, containing choriogenic-specific follicles (Fig. 1A).

The tissue-specific $\left(\mathrm{F}^{-/-}, \mathrm{M}, \mathrm{Ov}\right.$ and $\left.\mathrm{L}\right)$ Southern blotting technique (Sambrook et al., 1989) clearly demonstrates that the bPxd genetic locus does not follow any gene amplification rule, in all the tested DNA extracts (Fig. 1B). As it is illustrated in Fig. 1B, there were not any detectable differences observed of the obtained hybridization patterns among the various DNA extracts, strongly suggesting that the bPxd genetic locus is not specifically amplified during -late- oogenesis (choriogenesis), as it has been clearly demonstrated for the Drosophila six major chorion genes (S38, S36, S19, S18, S16 and S15).

\section{Ovarian-specific expression pattern of the bPxd gene}

The tissue-specific profile of the bPxd transcriptional activity was assessed in total RNA extracts purified from adult female flies without ovaries $\left(\mathrm{F}^{-/-}\right)$and ovarian $(\mathrm{Ov})$ tissues. Strong transcriptional expression of the bPxd gene was clearly detected in adult flies samples, as a major $2.9 \mathrm{~kb}$ thick band and a second $1.7 \mathrm{~kb}$ minor one. Interestingly, the positive signal observed in the ovarian extract corresponded to a $2.2 \mathrm{~kb}$ bPxd RNA transcript (Fig. 2). Since the bPxd peroxidase gene is represented only once (single copy gene) in the haploid version of the $B$. oleae genome (Fig. 1A), it is very likely that the $2.2 \mathrm{~kb}$ transcript is differentially produced through a tissue-specific alternative splicing (maturation) mechanism. Its weak representation observed in the ovarian tissue preparation (Fig. 2) (also confirmed by dot-blot RNA assays, data not shown) could be derived either by the low efficiency of the splicing (maturation) mechanism, or by the enhanced and strengthened post-transcriptional modification process directly resulting into the targeted RNA destabilization and degradation.

The complicated expression profile of the bPxd gene (three RNA transcripts of 2.9, 2.2 and $1.7 \mathrm{~kb}$ ) dictates the importance and physiological significance of its produced proteins (likely discrete peroxidase forms) in the development, function and behavior of a large variety of somatic $\left(\mathrm{F}^{-/-}\right)$and germ-line $(\mathrm{Ov})$
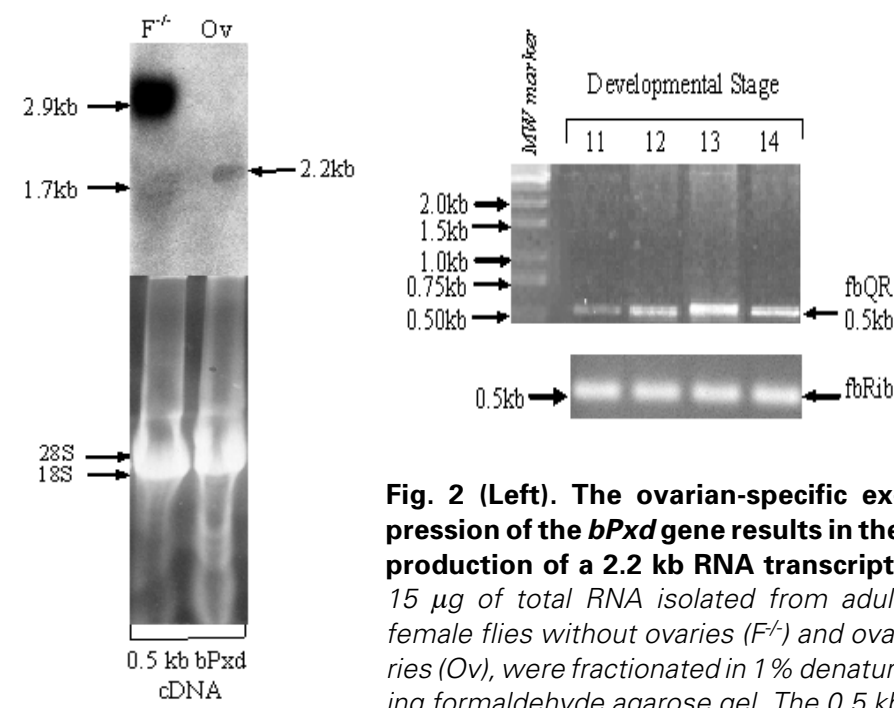

Fig. 2 (Left). The ovarian-specific expression of the $b P x d$ gene results in the production of a 2.2 kb RNA transcript. $15 \mu \mathrm{g}$ of total RNA isolated from adult female flies without ovaries $\left(\mathrm{F}^{-1}\right)$ and ovaries $(\mathrm{OV})$, were fractionated in $1 \%$ denaturing formaldehyde agarose gel. The $0.5 \mathrm{~kb}$ $\mathrm{bPxd} c D N A$ fragment isolated from $\mathrm{B}$. oleae choriogenic follicles was used as probe. All the analyzed RNA extracts were carefully quantified based on the $28 S$ and $18 S$ band-intensities, after ethidium bromide staining before transfer (bottom part). The production of an ovarianspecific $2.2 \mathrm{~kb}$ RNA transcript (Ov) and two additional 2.9 and $1.7 \mathrm{~kb}$ distinct RNA transcripts $\left(\mathrm{F}^{-/}\right)$(upper part) are indicative of the presence of a tissue-specific alternative splicing (maturation) mechanism.

Fig. 3 (Right). Developmental regulation of the $\boldsymbol{b} P \boldsymbol{P} d$ gene during late oogenesis (choriogenesis). RNA preparations from different stages of choriogenic follicles (11-14) were subjected to semi-quantitative RT-PCR using pQUE and pQUErev D. melanogaster Pxd gene-specific primers, finally resulting into the generation of a $0.5 \mathrm{~kb}$ fragment [ $\mathrm{fb} Q R$ ( $\mathrm{fb} Q R 11$ fbQR14)] (upper part). Amplification of a $0.5 \mathrm{~kb}$ B. oleae riboprotein gene fragment (fbRib) was also achieved (using the pRibf and pRibr D. melanogaster Rpb1 gene-specific primers), as a quantitative control of the reactions (bottom part). The highest level of bPxd RNA transcript accumulation was clearly detected during choriogenic stage 13 (fbQR13).

cells. Even though there is no conclusive evidence for the in vivo biological role of the somatic-specific 2.9 and $1.7 \mathrm{~kb}$ RNA transcripts, the germ-line (ovarian)-specific $2.2 \mathrm{~kb}$ RNA transcript likely encodes for the $B$. oleaechorion peroxidase, as it has been similarly suggested before, in the case of $D$. melanogaster Pxd homologous gene (Konstandi et al., 2005).

\section{Developmental regulation of the bPxd gene during choriogenesis}

The stage-specific expression profile of the bPxd gene during the late stages of oogenesis was detected by a semi-quantitative RT-PCR approach, performed on choriogenic (11-14) follicle total RNA preparations, using the $\mathrm{pQUE}$ and $\mathrm{pQUErev}$ specific primers (Fig. 3). The amplified RT-PCR products, of $0.5 \mathrm{~kb}$ each (fbQR11fbQR14), of the four developmental stages were agarose-electrophoresed and the obtained image was subsequently processed through a Gel Analyzer system (Biosure, Athens, Greece). Accurate quantitative analysis demonstrated that the bPxd folliclespecific RNA levels increase significantly from stage 11 up to 13, with a detectable reduction during stage 14 (Fig. 3). As expected, the fbRib RT-PCR fragment $(0.5 \mathrm{~kb})$, reflecting the response of the developmentally non-regulated gene bRpb1, was equally amplified in all the four stage-specific RNA extracts. The 4-fold (4 
A

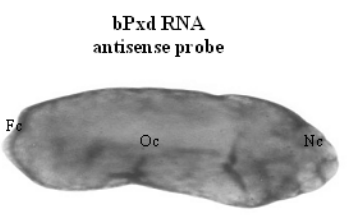

(a)

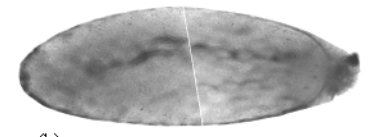

(b)

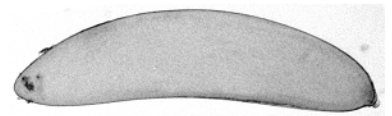

(c)
B

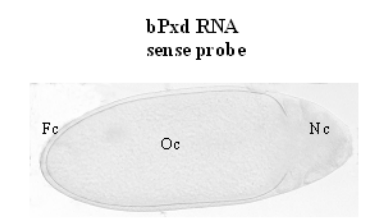

(a)

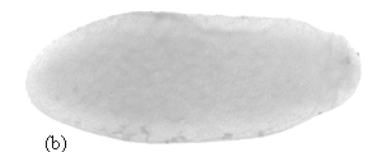

(b)

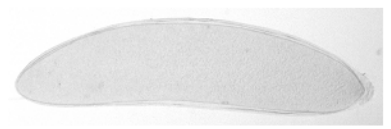

(c)

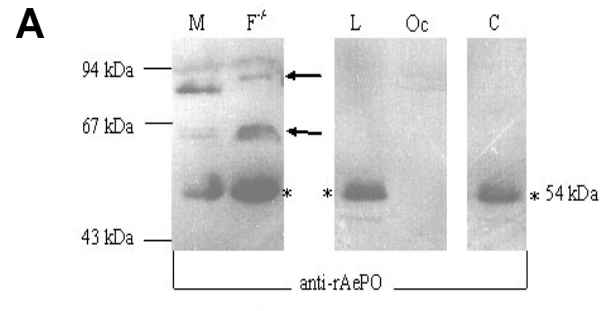

B

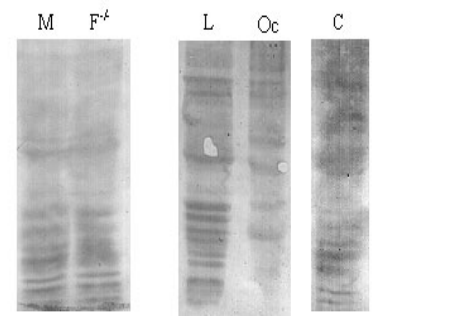

Fig. 4 (Left column). bPxd RNA transcripts are selectively detected in the follicle cell layer, but not in the oocyte. Stage-specific follicles (1214) were subjected to in situ hybridization using sense and antisense RNA probes, specifically generated from the $0.5 \mathrm{~kb} b \mathrm{Pxd} c D N A$ fragment ( $p G E M$ $T-b P x d$ recombinant plasmid), directly isolated from B. oleae dissected ovaries. (A) Antisense bPxd riboprobe. (B) Sense bPxd riboprobe (negative control). (a) Stage 12. (b) Stage 13. (c) Stage 14. The bPxd RNA transcripts are selectively localized in the follicle cell layer of all choriogenic stages (12-14), while the whole oocyte area is completely devoid of any detectable bPxd RNA transcript. Abbreviations: Fc, follicle cells; Nc, nurse cells; Oc, oocyte. Bar: $150 \mu \mathrm{m}$ (x 100).

Fig. 5 (Right column). A 54 kDa protein constitutes the B. oleae chorion enzymatic component (peroxidase). Crude protein extracts, isolated from adult male flies (M), female flies without ovaries $\left(F^{--}-\right)$, larvae $(\mathrm{L})$, oocytes $(\mathrm{OC})$ and extensively purified chorions $(\mathrm{C})$, were resolved by $12 \%$ denaturing SDS-PAGE gel electrophoresis. Subsequent Western blotting with the rabbit anti-rAePO polyclonal antibody revealed three immunoreactive bands [54 (major one: asterisk), 66 and $76 \mathrm{kDa}$ (minor ones: arrows), respectively] in both adult fly extracts [(M) and (F--)] and only one band, with a molecular weight of $54 \mathrm{kDa}$, in both larva (L) and chorion (C) preparations (asterisks). The complete absence of positive signals in the oocyte (Oc) protein extracts (also correlate with Figs. 4, 6 and 7) demonstrates the specificity of the immunodetection procedure employed. Protein quantification of all processed samples was achieved by Ponceau staining. (A) ECL-mediated Western blotting immunodetection, using the rabbit anti-rAePO polyclonal antibody. (B) Ponceau staining of the blotted nitrocellulose membrane after ECL treatment.

$x$ ) enhancement (software data not shown) of the bPxd RNA transcripts accumulation during stage 13 (compared to stage 11) could be likely attributed either to the post-transcriptional events controlling RNA stability, or to the differential efficiency of the splicing (maturation) process, which could be both tightly regulated in a stage-specific manner during late oogenesis. The chorion protein cross-linking reactions are activated during stage 14 , when the developing follicles and more specifically the chorionic layers, should be highly enriched with fully functional bPxd peroxidase activity (also correlate with Figs. 6 and 7).

One could easily envision a master regulatory mechanism of the coordinative transcriptional expression of all the chorionic genes (major and minor), essentially controlling the chorion dynamics and assembly. The above speculation is highly supported by the presence of the so-called "chorion box" (TCACGT cis-element) in the proximal promoter region $(-61)$ of the $D$. melanogaster Pxd homologous gene (Konstandi et al., 2005).

\section{Follicle cells, but not the oocyte, selectively produce bPxd RNA transcripts, as revealed by an in situ hybridization approach}

Staged (12-14) follicles were isolated in Ringer's solution and immediately subjected to a whole-mount in situ hybridization process (Fig. 4). Through the antisense riboprobe-mediated hybridization reactions we were able to demonstrate that the endogenous bPxd RNA transcripts were selectively synthe- sized in the epithelial follicle cells of all the choriogenic egg chambers tested (Fig. 4A). The production levels and accumulation rates of the bPxd RNA transcripts in the follicle cell subpopulations were significantly enhanced during stages 12 and 13 (Fig. 4A), elegantly confirming the results of the RT-PCR approach illustrated in Fig. 3. Interestingly, the whole oocyte area was found to be absolutely devoid of any detectable trace of the bPxd gene expression (no positive in situ hybridization reaction could ever be observed), strongly suggesting for the presence of a follicle cell layer-specific regulatory mechanism tightly controlling the bPxd transcriptional activity during late oogenesis. The specificity of our modified technical protocol was clearly documented by the absence of any positive signal developed in all the sense probe-mediated in situhybridization reactions (Fig. 4B). The follicle cell layer-specific bPxd gene expression is directly associated with the stage-specific activation of the $B$. oleae chorion peroxidase that plays an essential role in the completion of follicle maturation and chorion assembly/cross-linking.

\section{The enzymatic component of $\mathrm{B}$. oleae chorion is the $54 \mathrm{kDa}$ bPxd peroxidase}

In the preparations of male (M) and female without ovaries $\left(\mathrm{F}^{-/-}\right)$adult flies, one major immunoreacting band of $54 \mathrm{kDa}$ and two minor ones of 66 and $76 \mathrm{kDa}$, respectively, were developed after the completion of the Western blotting process with the ECL reagents (Fig. 5A). On the other hand, in chorion (C) and 
Fig. 6. Chorion-specific localization of the bPxd peroxidase: a light microscopy approach. (A) bPxd peroxidase was selectively immunodetected on the chorion structure (ch) (arrow) [in contrast to the whole oocyte area (oc)] of a representative stage 14 follicle, as it was clearly demonstrated by light microscopy observation of sections specifically incubated with the rabbit anti-rAePO polyclonal antibody (also correlate with Figs. 5 and 7). The secondary antibody used was the goat anti-rabbit lgG conjugated to the HRP enzyme. (B) No positive signal was ever observed when either the primary antibody (rabbit anti-rAePO), or the secondary antibody (goat anti-rabbit lgG-HRP) (data not shown), was omitted (negative controls). Bars: $30 \mu \mathrm{m}$ (x 1.300).

larva (L) extracts only one protein band, having a molecular weight (MW) of $54 \mathrm{kDa}$ and exhibiting a strong binding affinity with the anti-rAePO polyclonal antibody, could be easily detected (Fig. 5A). Interestingly, the oocyte (Oc) sample (proven to be a valuable internal negative control) did not seem to contain any immunoreacting component, demonstrating the specificity of our technical protocol (Fig. 5A). Figure 5B illustrates the Ponceau staining of the nitrocellulose membrane, after ECL treatment, verifying the comparable protein concentration, gel loading and electro-transfer efficiency among all the analyzed crude extracts ( $\mathrm{M}, \mathrm{F}^{-/}, \mathrm{L}, \mathrm{Oc}$ and $\left.\mathrm{C}\right)$. As it has been previously observed for the homologous Pxd protein, the $D$. melanogasterchorion peroxidase $(55 \mathrm{kDa})$ was found to be 22 $\mathrm{kDa}$ smaller than the putative protein deduced from the fulllength cDNA clone (77 kDa) (Konstandi et al., 2005). Thus, the $54 \mathrm{kDa} B$. oleaechorionic component could be likely generated by distinct follicle-specific post-translational proteolytic cleavages of the $76 \mathrm{kDa}$ precursor protein, as similarly shown for the Aedes aegypti AePOx peroxidase (Zhao et al., 2001) and strongly suggested for the $D$. melanogaster $P x d$ peroxidase (Konstandi et al., 2005). The rabbit anti-rAePO polyclonal antibody was raised against the $A$. aegypti $\mathrm{AePOx}$ peroxidase and could immunorecognize, with comparable binding specificity and affinity, both the recombinant Pxd ( $\mathrm{rPxd}$ ) peroxidase [produced by the Pichia pastoris expression system (Konstandi
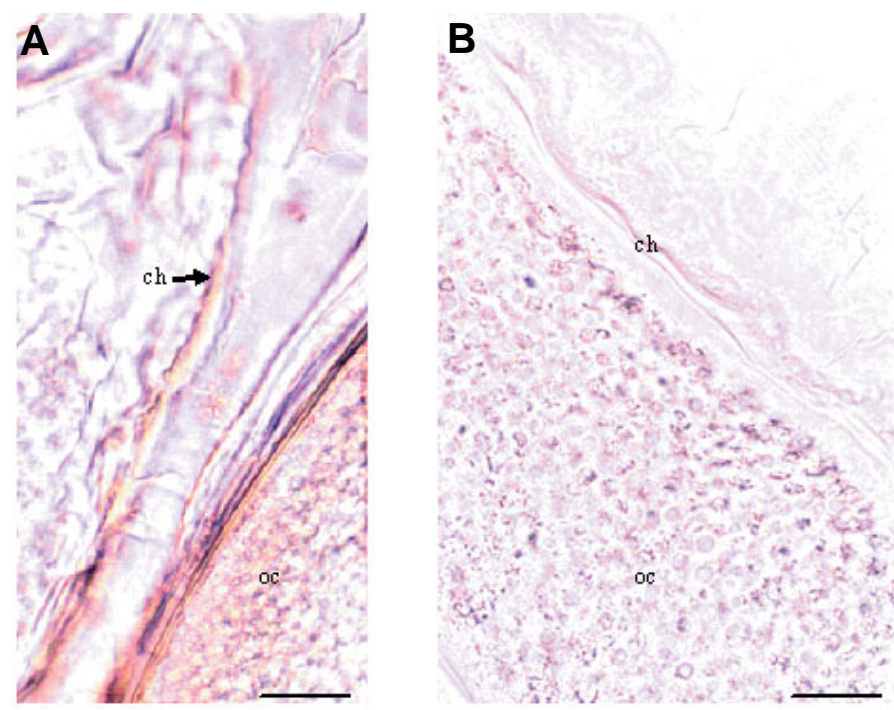

et al., 2005)] and the $54 \mathrm{kDa}$ protein of the $B$. oleae chorionic extracts (Fig. 5; data not shown). In sum, all the above data indicate that the essential enzymatic component of the $B$. oleae chorion structure is the $54 \mathrm{kDa}$ bPxd peroxidase, likely produced through an ovarian (follicle)-specific proteolytic process.

\section{One of the essential structural elements of B. oleae chorion is $b P x d$ peroxidase}

The rabbit anti-rAePO polyclonal antibody was used to reveal the specific localization and distribution of $B$. oleae chorion peroxidase molecules in both light and electron microscopy sections of staged (14) follicles, during late oogenesis. All the light microscopy sections were treated with the goat antirabbit IgG conjugated to the HRP enzyme, as the secondary antibody (Fig. 6), while the goat anti-rabbit IgG conjugated to 10 $\mathrm{nm}$ gold particles was selected as the secondary antibody for all
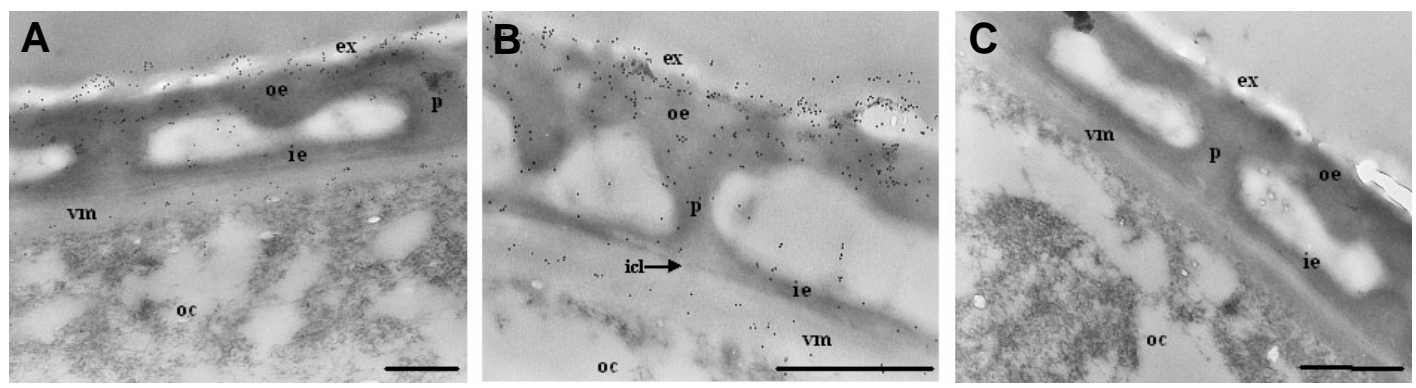

Fig. 7. B. oleae chorion structure is highly enriched with bPxd peroxidase molecules in all its successive layers: an immunogold labelling (TEM) approach. Ultrastructural immunolocalization of the bPxd peroxidase on all the consecutive structural stratums of a representative stage 14 chorion assembly, revealed by an immunogold labelling protocol with transmission electron microscopy (TEM) sections. (A) Cross section of the B. oleae chorion structure, after being immunolabelled with the rabbit anti-rAePO polyclonal antibody. (x 26.000). (B) Higher magnification view (x 56.000) of a thin-sectioned (stage 14) follicle preparation similar to (A). Goat anti-rabbit IgG conjugated to $10 \mathrm{~nm}$ gold particles was used as the secondary antibody for $(A, B, C)$. It is apparent from both $(A)$ and $(B)$ that all the chorionic successive layers are characterized by a high density of bPxd peroxidase molecules, which are distributed rather unevenly, without a regular pattern, all over the chorionic surface. It has been repeatedly observed that the exochorion (ex) and the outer endochorion (oe) exhibit significantly higher gold particle densities in comparison with the pillars (p), the inner endochorion (ie) and the innermost chorionic layer (ICL). The biological importance of this differential accumulation is still unknown and needs further exploration. The thick vitelline membrane $(\mathrm{vm})$ is also specifically labelled, whereas the whole oocyte area (oc) and the surrounding resin are virtually devoid of gold particles (also correlate with Figs. 5 and 6). (C) Control section, involving omission of the primary rabbit anti-rAePO polyclonal antibody, of a representative late stage (14) choriogenic follicle. No gold particles were observed. (x 38.000). Bars: $0.5 \mu \mathrm{m}$. 
the electron microscopy immunodetections (Fig. 7). In both approaches, strong positive signals were clearly observed in distinct areas of chorion structure. On the other hand, whenever either the primary or the secondary antibody was omitted (negative controls) from the immunoreaction procedure no signal could ever be obtained (Figs. 6B and 7C), demonstrating the specificity of our technical protocol.

Figure $6 \mathrm{~A}$ reveals that the bPxd peroxidase is selectively localized in the chorion structure (ch) of a stage 14 follicle and, as expected (Fig. 5A), is completely absent from the whole oocyte area (Oc) (also see Fig. 7). More specifically, as it is clearly shown in Fig. 7 ( $A$ and $B$ ), a large number of gold particles could be easily detected in the exochorion (ex), the outer endochorion (oe), the pillars (p), the inner endochorion (ie), the innermost chorionic layer (ICL) and the thick vitelline membrane (vm). Interestingly, all the successive chorionic layers are characterized by an enriched and high density dispersed pattern of the bPxd protein distribution (as reflected by the abundance of the $10 \mathrm{~nm}$ gold particles), strongly indicating the essential structural role of the bPxd peroxidase in the chorion assembly process, during $B$. oleae late oogenesis.

\section{Discussion}

Significant conservation of chorion genes (chromosomal loci, coding sequences and promoter regulatory elements) has been observed in all Diptera species studied so far, including Drosophila, Bactroceraand Ceratitis (Foster et al., 1981; Vlachou et al., 1997). Several highly preserved features have been reported, while novel and unique events during molecular evolution have been clearly identified. One of the most impressively conserved characteristics is the presence of extremely homologous gene clusters in Drosophila, Bactrocera and Ceratitis, organized with the same order and orientation. This genetic invariability for approximately 120 million years (Beverley and Wilson, 1984) is in striking contrast to the radical differences in chorion gene structure and organization in between fly and silkmoth species, which have been separated twice as long in evolution (Sourmeli et al., 2003). The proteins encoded by chorion genes of various Diptera species have retained sufficient similarities at the sequence level to be identified with their Drosophila homologous members, but have otherwise diverged drastically, confirming the generalization that chorion proteins evolved very rapidly (Martinez-Cruzad et al., 1988).

All the chorion genes are selectively expressed in the follicle cell layer during the late stages of oogenesis (choriogenesis). Structural analysis of their proximal promoter regions has revealed the presence of a hexamer nucleotide cis-regulatory sequence, "TCACGT" (also known as "chorion box"), which has been found to be identical not only in a large variety of Drosophila species, but in other insects as well, such as $C$. capitata and Bombyx mori(Sourmeli et al., 2003). Interestingly, the "TCACGT" sequence has been also observed in the Drosophila Pxd proximal promoter region (along with additional common cis-regulatory elements), likely regulating the Pxd peroxidase gene transcriptional activity during choriogenesis (Konstandi et al., 2005; data not shown). Comparative sequence analysis of the Pxd, S38 and $\mathrm{S} 15$ proximal promoter regions revealed the presence of distinct transcription-controlling elements, including the "TCACGT" "chorion box" (data not shown), strongly suggesting that a common regulatory mechanism could be directly involved in the coordinative transcriptional regulation of peroxidase and chorion genes.

The conserved genome organization and structure within Diptera species may be related to the apparently ancient, with the exception of silk moths, invention of a chorion gene amplification developmental mechanism that allows the rapid chorion formation, during late oogenesis, through the activation of a small number of structural genes (Spradling and Mahowald, 1980; Spradling, 1981; Osheim and Miller, 1983; Osheim et al., 1988).

In the present study, we demonstrate an extremely strong level of conservation, concerning the essential physiological roles of chorion peroxidase in both $D$. melanogaster (Konstandi et al., 2005) and $B$. oleae (this report) Diptera species, as revealed by comparative: (a) partial cDNA sequence analysis, (b) genetic locus rough organization, (c) stage- and cell-specific transcriptional expression patterns, (d) gene product immunocharacterization and (e) peroxidase immunolocalization.

Comparative DNA sequence analysis revealed a striking identity of $98 \%$ in between the $0.5 \mathrm{~kb}$ RT-PCR cDNA fragment (likely encoding for the putative catalytic domain of the enzyme) of the $B$. oleae bPxd gene and the $D$. melanogasterPxd peroxidase gene, which was previously reported to encode for the critical enzymatic component of the $D$. melanogaster chorion structure (Konstandi et al., 2005). The bPxd putative peptide exhibits significant amino acid similarities with distinct invertebrate peroxidase family members (data not shown), including the Pxd (Konstandi et al., 2005), the AePOx (Zhao et al., 2001), the Pxt (Vasquez et al., 2002) and the $A$. aegyptiCPO protein ( $\mathrm{Li}$ et al., 2004).

As it is clearly revealed by Southern blotting analysis, the $B$. oleae genome contains a single copy bPxd gene, which is not differentially amplified during choriogenesis, in the contrary to what has been previously shown for the six major chorion genes (Vlachou et al., 1997). These observations could likely substantiate the dual essential role of the bPxd gene product in the chorion assembly process during late oogenesis. Even though the bPxd peroxidase represents a fundamental structural component of $B$. oleae chorion (Figs. 5, 6 and 7), the demands for enhanced protein synthesis seem to be accomplished without the involvement and activation of a gene amplification process. On the other hand, the six major chorion genes follow a developmentally regulated amplification program, resulting in the production of large amount of proteins with essential structural roles in the chorion assembly and organization (Vlachou et al., 1997). Thus, the molecular stoichiometry, regarding the participation ratio in the chorion structure, between the bPxd peroxidase and a representative chorionic protein (one out of six), could be likely favored over the latter $(1:>1)$, indicating the presence of major differences between their regulatory networks tightly controlling either the mRNA or protein stability. Moreover, the potential ability of the bPxd peroxidase to "flow around" the "chorionic micro-environment", performing its enzymatic cross-linking functions, could be directly associated with the absence of an amplification process, since adequate levels of protein production could be achieved through a single transcriptional activation mechanism.

Two RNA transcripts (2.9 and $1.7 \mathrm{~kb}$, respectively) of the bPxd 
gene are observed in total RNA extracts from adult flies $\left(\mathrm{F}^{-/-}\right)$, while the $B$. oleae isolated ovaries $(\mathrm{Ov})$ are characterized by a single $2.2 \mathrm{~kb}$ RNA transcript. This tissue-specific expression pattern could be likely resulted by the activation of a developmentally regulated alternative splicing (maturation) process. We strongly believe that ovarian-specific distinct splicing factors are directly involved in the generation of $2.2 \mathrm{~kb}$ mature transcripts from precursor RNA molecules that either are provided maternally or are de novo synthesized in the follicle cell layer. In both cases, our inability to detect high molecular weight RNA precursor transcripts dictates the occurrence of a high efficiency and fidelity ovarian-specific differential splicing (maturation) mechanism.

As it is demonstrated by an RT-PCR approach (Fig. 3), the bPxd gene activity can be clearly detected throughout the whole choriogenic period (stages 11-14), exhibiting the highest RNA accumulation levels during stage 13. Even though in stage 14 of oogenesis the bPxd RNA levels are somehow diminished, they still remain traceably higher than the ones observed in stages 11 and 12. The developmental control of the bPxd gene expression could be mediated either by a stage 13 up-regulated transcriptional mechanism, or by a stage 11 up-regulated post-transcriptional RNA destabilization (degradation) process. The strongest accumulation of the bPxd ovarian-specific RNA transcripts during stage 13 is directly associated with the completion of follicle maturation and developmental activation of chorion peroxidase function, both occurring during stage 14 of $B$. oleae late oogenesis.

The in situhybridization technology clearly demonstrates the follicle cell-specific production of the bPxd RNA transcripts, also revealing their complete absence from the developing oocyte. This differential bPxd gene expression during late oogenesis could be likely attributed to a cell-specific transcriptional activation mechanism, without being able to exclude distinct posttranscriptional RNA stabilization events. Using both RT-PCR (Fig. 3) and in situ hybridization (Fig. 4) approaches, we have clearly shown that the developmental period of the ovarianspecific highest bPxd RNA transcripts accumulation is designated at stage 13, even though adequate levels of agglomerated RNA transcripts can be also detected during all the choriogenic stages tested. The follicle cell layer-specific bPxd RNA expression levels are highly enriched at both the anterior and posterior pole of stage 13 follicles (data not shown), an observation that is directly associated with the specific staining obtained when isolated $B$. oleae follicles are treated in vitro with either guaiacol or o-diaminobenzidine, two widely used synthetic compounds capable of sensitively detecting peroxidase activity (data not shown).

When protein extracts from male (M) and female without ovaries $\left(\mathrm{F}^{-/}\right)$flies were subjected to Western blotting analysis, one major band of $54 \mathrm{kDa}$ and two minor ones of 66 and $76 \mathrm{kDa}$, respectively, could be specifically immunodetected. Interestingly, in the larva $(\mathrm{L})$ and chorion $(\mathrm{C})$ crude protein extracts only one thick band was clearly identified at $54 \mathrm{kDa}$ (Fig. 5). As expected by the in situhybridization results (Fig. 4), the oocyte (Oc) protein preparation was found to be devoid of any detectable signal, even after long exposures of the corresponding autoradiographs (data not shown). Since the primary rabbit polyclonal antibody was raised against the $A$. aegypti AePOx peroxidase, we strongly believe that the $54 \mathrm{kDa}$ protein represents the $B$. oleae chorion peroxidase, which appears to contain strong antigenic similarities with the AePOx homologous protein (Fig. 5). These conclusions are also highly supported by: (a) the comparable strong binding affinity of the rabbit anti-rAePO polyclonal antibody either onto the D. melanogasterrecombinant Pxd ( $\mathrm{rPxd}$ ) peroxidase (Konstandi et al., 2005), or the B. oleae $54 \mathrm{kDa}$ chorionic protein (Fig. 5; data not shown), combined with (b) the impressive nucleotide identity (98\%, data not shown) in between the $D$. melanogasterfull-length Pxd cDNA clone and $B$. oleae partial $(0.5 \mathrm{~kb})$ bPxd cDNA fragment.

The $54 \mathrm{kDa}$ peroxidase is likely produced through a posttranslational proteolytic process, specifically activated in various subpopulations of the follicle cell layer during choriogenesis. Similarly, distinct proteolytic cleavages, probably occurring in a tissue-specific manner, of the $76 \mathrm{kDa}$ precursor molecules could be directly involved in the generation of the 66 and $54 \mathrm{kDa}$ proteins detected in the adult flies ( $\mathrm{M}$ and $\mathrm{F}^{-/-}$) extracts.

The activated peroxidases are targeted to annihilate the destructive capacity of oxygen radical species, demonstrating their essential roles into the defense and detoxification systems of these tissues. Thus, it is very likely that the 76, 66 and $54 \mathrm{kDa}$ proteins could confer similar protection shields against oxygen radicals-mediated destruction in the cell populations they are selectively produced. Having established that the completion of $B$. oleaeoogenesis is mainly characterized by the $\mathrm{H}_{2} \mathrm{O}_{2}$-mediated chorion hardening (Mouzaki and Margaritis, 1991a; Margaritis and Mazzini, 1998), it seems reasonable to speculate that the 54 $\mathrm{kDa}$ peroxidase is directly involved in both the protein crosslinking process and the detoxification protection mechanism of the developing follicles. Since there are a limited number of reports describing the in vivo physiological functions of various peroxidases in different tissues, such as the nervous system (Ichmiya et al., 1997) and muscle (Knopp et al., 1999), the extensive study of the bPxd protein forms in B. oleaedevelopment and morphogenesis is an extremely important biological issue that needs further exploration.

Both Light (Fig. 6) and Transmission Electron Microscopy (Fig. 7) immunodetection approaches have unambiguously confirmed the Western blotting analysis data (Fig. 5), clearly revealing the chorion-specific localization of the $B$. oleae bPxd peroxidase. As expected, all the immunoreacting areas are restricted in the chorion structure (ch) and the vitelline membrane (vm), while the oocyte (oc) is completely deprived from the presence of any detectable bPxd protein. More specifically, as it is shown by the immunogold labelling technology, the bPxd peroxidase is specifically observed at a high density in all the successive chorionic layers of a stage 14 developing follicle. As illustrated in Fig. 7, the exochorion (ex), the endochorionic sub-layers [outer endochorion $(o e)$, pillars ( $p$ ) and inner endochorion (ie)], the innermost chorionic layer (ICL) and the thick vitelline membrane (vm) are all highly enriched in gold particles (bPxd proteins), strongly indicating the essential biological significance and contribution of the bPxd peroxidase in the $B$. oleaechorion physiology. Interestingly, it was previously reported for $B$. oleaespecies, through an in situ cytochemistry approach, that, beyond the chorionic layers, the vitelline membrane also contains a strong $\mathrm{H}_{2} \mathrm{O}_{2}$-regulated peroxidase activity (Margaritis, 1985a). The strong immunoreactivity of the rabbit anti-rAePO polyclonal antibody with the $54 \mathrm{kDa}$ chorionic component (Fig. 5), in combination with the dense topology and abundance of the gold particles (Fig. 7), strongly suggest for 
the presence of a dual fundamental role of the bPxd peroxidase in chorion structure and assembly. In other words, the $54 \mathrm{kDa}$ protein form most likely constitutes an essential and critical structural element of the $B$. oleae chorion scaffold, being in all probability also responsible for the chorion hardening process, through a $\mathrm{H}_{2} \mathrm{O}_{2}$-dependent and di- / tri-tyrosine bond-mediated protein cross-linking mechanism.

All the above data, reported for the first time in the present study, strongly support the notion that the chorion peroxidase is a highly conserved (structurally and functionally) protein among Diptera species and especially among insects with significant economic impact and importance. The evolutionary conserved and most likely dual (enzymatic and structural) fundamental role of chorion peroxidase in the formation of a physiologically assembled and completely functional chorion structure could allow us to propose the development of a novel bPxd-dependent sterile insect technique (SIT) protocol, bearing highly efficient and powerful biological properties. Interestingly, a preliminary study has been previously reported, in which in vivo treatment with the potent peroxidase inhibitor phloroglucinol resulted in the production of non-matured and finally non-survived eggs (Keramaris et al., 1996). Alternatively, the chorion peroxidase gene could be easily considered as a suitable target locus for the development of genetically engineered insect strains, in order to produce novel and unique biological control methods for auspicious pest management.

\section{Materials and Methods}

All tissues used in the present study (adults, larvae, follicles and eggs) derived from a wild type strain $B$. oleae flies culture being collected in Ringer's medium at $25^{\circ} \mathrm{C}$, in a walk-in environmental chamber.

\section{Strains and growth media}

The $\mathrm{DH} 5 \alpha$ Escherichia colibacterial strain was used for the cloning steps and final propagation of the pGEM-T-bPxd recombinant plasmid (see below).

\section{Semi-quantitative RT-PCR}

Follicles of discrete choriogenic stages (11-14) ( 30/stage) were hand-dissected in Ringer's solution and subsequently subjected to RTPCR (Reverse Transcription-Polymerase Chain Reaction), using the RETROSCRIPT kit (Ambion), according to the supplier's recommendations. $200 \mathrm{ng}$ of total RNA were used for the RT-PCR reactions. The DNA sequences of the specific primers pQUE-pQUErev and the PCR protocol used are given elsewhere (Konstandi et al., 2005). All the RNA preparations were quantitated by pRibf- and pRibr-mediated PCR reactions, which could specifically amplify part of the $B$. oleae Rpb1 gene. The 0.5 $\mathrm{kb}$ cDNA fragment (bPxd) was subcloned into the pGEM-T-easy vector (Promega), as recommended by the manufacturer.

\section{DNA sequencing}

Sequencing reactions were performed by the MWG-Biotech Company. The obtained results were analyzed using the BLAST software from NCBI.

\section{Southern blotting}

Genomic DNA was prepared from $B$. oleaeadult flies (females without ovaries and males), larvae and ovaries, according to Holmes and Bonner protocol (1973). Purified DNA was digested with the appropriate restriction endonucleases, size fractionated in a $1 \%$ agarose gel and finally blotted overnight onto a nylon membrane (Amersham), according to
Sambrook et al. (1989). The radioactive ${ }^{32} \mathrm{P}-\mathrm{dATP}$ cDNA probe $(0.5 \mathrm{~kb}$ bPxd cDNA fragment) was generated using a random priming labelling kit (Promega), following the manufacturer's instructions. All the hybridization reactions were performed into a Church hybridization buffer, under high stringency conditions $\left(65^{\circ} \mathrm{C}\right)$.

\section{Northern blotting}

Total RNA was prepared, according to Jacobs-Lorena protocol (1980), as modified by Bouhin et al. (1992), from ovary-ectomized female adult flies $\left(\mathrm{F}^{-/-}\right)$and ovaries (Ov). The RNA extracts (15 $\mu \mathrm{g}$ each) were separated in a denaturing formaldehyde $1 \%$ agarose gel and subsequently transferred onto a nylon membrane (Amersham), according to Sambrook et al. (1989). The filters were hybridized with a randomly labelled ${ }^{32} \mathrm{P}-\mathrm{dATP} \mathrm{cDNA}$ probe $(0.5 \mathrm{~kb}$ bPxd cDNA fragment), under high stringency conditions $\left(65^{\circ} \mathrm{C}\right)$.

\section{In situ hybridization}

Sense and antisense riboprobes were generated against the cloned $0.5 \mathrm{~kb}$ bPxd cDNA fragment (pGEM-T-bPxd recombinant construct) and in situhybridization reactions were performed as following: ovaries were dissected into Ringer's solution and fixed in solution I (2 mM MgSO4, 0.1 $\mathrm{M}$ Hepes $\mathrm{pH}$ 6.9, $1 \mathrm{mM}$ EDTA and $4 \%$ formaldehyde) for $30 \mathrm{~min}$ at room

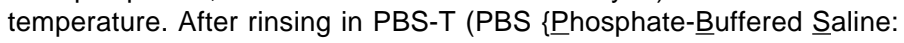
$\left.0.137 \mathrm{M} \mathrm{NaCl}, 2.7 \mathrm{mM} \mathrm{KCl}, 4.3 \mathrm{mM} \mathrm{Na}_{2} \mathrm{HPO}_{4}, 1.47 \mathrm{mM} \mathrm{KH}_{2} \mathrm{PO}_{4}, \mathrm{pH} 7.4\right\}$ $+0.05 \%$ Tween-20) for $20 \mathrm{~min}$, the follicles were incubated for $20 \mathrm{~min}$ in PBS-T containing $4 \mathrm{mg} / \mathrm{ml}$ non-predigested Proteinase $\mathrm{K}$ (Sigma). Prehybridization and initial washes in hybridization buffer (50\% formamide, $5 X$ SSC, $0.1 \%$ Tween-20, $100 \mu \mathrm{g} / \mathrm{ml}$ salmon sperm and $100 \mu \mathrm{g} / \mathrm{ml}$ heparin) were all performed at $56^{\circ} \mathrm{C}$. Alkaline phosphatase (AP)-conjugated anti-digoxigenin antibody (Boehringer-Manheim) was used in a dilution of $1: 2000$. Following rinsing and staining reactions [APB $(100 \mathrm{mM}$ $\mathrm{NaCl}, 50 \mathrm{mM} \mathrm{MgCl}, 100 \mathrm{mM}$ Tris- $\mathrm{HCl} \mathrm{pH}$ 9.5, levamisole and $0.1 \%$ Tween-20, $0.38 \mathrm{mM} \mathrm{BCIP}$ \{5-Bromo-4-chloro-3-indonyl-phosphate $\}$ and $0.41 \mathrm{mM}$ NBT \{4-Nitrobluetetrazolium-chloride\})], the treated follicles were spread onto poly-L-lysine coated slides overlaid with mounting media. Samples were observed with an OLYMPUS BH-2 light microscope.

\section{Western blotting}

Adult flies (males and females without ovaries), larvae, ovaries and purified chorions were homogenized in the appropriate solubilization buffer, containing $6 \mathrm{M}$ urea, $10 \mathrm{mM}$ Tris- $\mathrm{HCl} \mathrm{pH} 8.4,1 \%$ SDS and $4 \% \beta$ mercaptoethanol. The homogenates were centrifuged at $12.500 \mathrm{rpm}$ $(15.000 \times \mathrm{g})$ for $10 \mathrm{~min}$, in order to obtain soluble proteins. An additional treatment of 20 min vortexing was performed in the case of the chorion preparations. All the protein extracts were resolved in a 12\% SDS-PAGE denaturing gel electrophoresis, as described by Laemmli (1970), on a BIORAD miniprotean apparatus. The separated proteins were electrotransferred onto a nitrocellulose membrane (Amersham), with a solution containing $25 \mathrm{mM}$ Tris-base, $200 \mathrm{mM}$ glycine, 20\% methanol and $0.04 \%$ SDS. The bPxd peroxidase was immunodetected using a rabbit antirAePO polyclonal antibody, at a final dilution of 1:2000 in blocking buffer [TBS-T (TBS \{ Tris-Buffered Saline: $10 \mathrm{mM}$ Tris- $\mathrm{HCl} \mathrm{pH} \mathrm{7.4,} 150 \mathrm{mM}$ $\mathrm{NaCl}\}+0.05 \%$ Tween-20) and $5 \%$ non-fat milk] and visualized using the ECL system (Amersham-Pharmacia).

\section{Light microscopy (LM)}

$B$. oleae ovaries were dissected in Ringer's solution. Whole ovaries, or separated follicles, of late developmental (choriogenic) stages where fixed for 120 min (at $4^{\circ} \mathrm{C}$ ) in $\mathrm{PBS} \mathrm{pH} 7.2$, containing 4\% paraformaldehyde (electron microscopy grade, Polysciences Inc., Warrington, Pennsylvania, USA). Following fixation, the ovaries, or follicles, were washed twice for $20 \mathrm{~min}$ in PBS at $4^{\circ} \mathrm{C}$ and incubated in PBS pH 7.2, containing $0.1 \mathrm{M}$ glycine, for 90 min at $4^{\circ} \mathrm{C}$, in order to quench the free aldehyde groups. Afterwards, the samples were washed twice in PBS, properly dehydrated 
(through graded series of ethanol solutions) and finally embedded in Unicryl resin (British Biocell International, Cardiff, Wales, UK). The resin was UV-polymerized for $72 \mathrm{~h}$ at $4^{\circ} \mathrm{C}$. The Unicryl resin sections $(1 \mu \mathrm{m}$ thick) were placed onto poly-L-lysine covered slides and, after equilibration and blocking, incubated for $60 \mathrm{~min}$, at room temperature, with the rabbit anti-rAePO polyclonal antibody, diluted 1:100 in blocking buffer. After rinsing the sections in TBS-T, the secondary antibody [goat antirabbit IgG-HRP (Amersham: NA-934)] was applied, diluted 1:30 in blocking buffer. The immunoreacting areas were revealed with $0.03 \% \mathrm{H}_{2} \mathrm{O}_{2}$ and $0.06 \%$ diaminobenzidine (DAB), in $50 \mathrm{mM}$ Tris- $\mathrm{HCl} \mathrm{pH} \mathrm{7.6,} \mathrm{for} 5 \mathrm{~min}$, without haematoxylin counterstaining. Mounted slides for LM immunodetections were examined with an OLYMPUS BH-2 light microscope.

\section{Transmission electron microscopy (TEM)-immunogold labelling}

$B$. oleae dissected ovaries, or follicles, were fixed, dehydrated and finally embedded in Unicryl resin, as described above. Appropriate sections were cut to silver interference colors $(50-70 \mathrm{~nm})$ and floated onto plain 400 mesh nickel grids (Pelco International, Redding, England, UK). The grids were subsequently processed for a TEM immunogold labelling approach, as previously described (Antonelou et al., 2003). Briefly, the TEM sections were initially blocked in PBS, containing $3 \%$ fatty acid-free bovine serum albumin (BSA) and $0.1 \%$ Tween-20, for $45 \mathrm{~min}$ and subsequently incubated with the, mosquito-specific, rabbit anti-rAePO polyclonal antibody, diluted 1:20 in blocking solution for 90 min. After extensive washes in PBS, the treated grids were incubated with the goat anti-rabbit IgG conjugated to $10 \mathrm{~nm}$ gold particles secondary antibody (EM.GRHL10, British Biocell International, Cardiff, Wales, UK), diluted $1: 150$ in blocking solution for $60 \mathrm{~min}$. Following the final washes with PBS and $\mathrm{ddH}_{2} \mathrm{O}$, the sections were stained with a $3 \%$ aqueous uranyl acetate solution for 10 min and analyzed on a Phillips EM 300 electron microscope, operating at $80 \mathrm{kV}$. All the incubation and washing steps were carried out at room temperature. The applied immunolabelling negative controls (omission of the primary, or secondary, antibody) did not reveal any detectable immunoreactivity, demonstrating the specificity of our immunogold labelling protocol.

\section{Acknowledgements}

The rabbit anti-rAePO polyclonal antibody, raised against the A. aegypti AePox peroxidase, was kindly provided by Professor $B$. Christensen (Department of Animal Health \& Biomedical Sciences, University of Wisconsin-Madison). We are deeply grateful to Associate Professor K. Komitopoulou (Faculty of Biology, University of Athens) for her generous gift of the pRibf and pRibr primers. O. Konstandi was financially supported by a fellowship awarded from the Greek Foundation for Fellowships (IKY). The present study was funded by a TMR grant $N^{\circ}$ EBR4061PL970047, assigned to Professor L. H. Margaritis.

D. J. Stravopodis would like to devote this paper to the memory of his precious and unique friend Dr. Alexandros Argyrokastritis, who so unfairly passed away.

\section{References}

ANTONELOU, M.H., PAPASSIDERI, I.S., KARABABA, F.J., STRAVOPODIS, D.J., LOUTRADI, A. and MARGARITIS, L.H. (2003) Defective organization of the erythroid cell membrane in a novel case of congenital anaemia. Blood Cel/s Mol. Dis. 30(1):43-54.

ANWAR, M., CHAMBERS, D.L., OHINATA, L. and KOBAYASHI, R.M. (1971) Radiation sterilization of the Mediterranean fruit fly (Diptera: Tephritidae): comparison of spermatogenesis in flies treated as pupae or adults. Ann. Entomol. Soc. Am. 64:627-633.

BEVERLEY, S.M. and WILSON, A.C. (1984) Molecular evolution in Drosophila and the higher Diptera. II. A time scale for fly evolution. J Mol Evo/41:1-13.

BOUHIN, J.P., QUENNEDEY, J. and DELACHAMBRE, J. (1992) Developmental profiles of epidermal mRNAs during the pupa-adult molt of Tenebrio moliturand isolation of a cDNA clone encoding an adult cuticular protein: effects of a juvenile hormone analogue. Dev. Biol. 149:112-122.

FOSTER, G., WHITEN, G.M., KONOVALOV, C., ARNOLD, S.T.A. and MAFFI, M. (1981) Autosomal genetic maps of the Australian Sheep Blowfly, Lucillia cuprina dorsalis $R$ - $D$ (Diptera: Calliphoridae) and possible correlations with the linkage maps of Musca domestica Land Drosophila melanogaster(Mg.). Genet. Res. 37:55-69.

HOLMES, S. and BONNER, J. (1973) Preparation, molecular weight, base composition and secondary structure of giant nuclear ribonucleic acid. Biochemistry 12:2330-2338.

ICHIMIYA, S., DAVIS, J.G., O'ROURKE, D.M., KATSUMATA, M. and GREENE, M.I. (1997) Murine thioredoxin peroxidase delays neuronal apoptosis and is expressed in areas of the brain most susceptible to hypotoxic and ischemic injury. DNA Cel/ Biol. 16:311-321.

JACOBS-LORENA, M. (1980) Dosage of 5 S and ribosomal genes during oogenesis of Drosophila melanogaster. Dev. Biol. 80:134-145.

KERAMARIS, K.E., MARGARITIS, L.H., ZOGRAFOU, E.N. and TSIROPOULOS, G.J. (1996) Egg laying suppression in Drosophila melanogaster (Diptera: Drosophilidae) and Dacus (Bactrocera) oleae (Diptera: Tephritidae) by phloroglucinol, a peroxidase inhibitor. Bull. Entom. Res. 86:369-375.

KNOPP, E.A., ARNDT, T.L., ENG, K.L., CALDWELL, M., LEBOEUF, R.C., DEEB, S.S. and O'BRIEN, K.D. (1999) Murine phospholipid hydroperoxide glutathione peroxidase: cDNA sequence, tissue expression and mapping. Mamm. Genome 10:601-605.

KONSTANDI, O.A., PAPASSIDERI, I.S., STRAVOPODIS, D.J., KENOUTIS, C.A., HASAN, Z., KATSORCHIS, T., WEVER, R. and MARGARITIS, L.H. (2005) The enzymatic component of Drosophila melanogaster chorion is the Pxd peroxidase. Insect Biochem. Mol. Biol. 35:1043-1057.

LAEMMLI, U.K. (1970) Cleavage of structural proteins during the assembly of the head of the bacteriophage T4. Nature 227:680-685.

LI, J., KIM, S.R. and LI, J. (2004) Molecular characterization of a novel peroxidase involved in Aedes aegyptichorion protein cross-linking. Insect Biochem. Mol. Biol. 34:1195-1203.

LOUIS, C., SAVAKIS, C. and KAFATOS, F.C. (1987) Possibilities for genetic engineering in insects of economic interest. Proceedings of the Second International Symposium in Fruit Flies, Edited by A. P. Economopoulos, Elsevier, Amsterdam, pp 4-57.

LOUKERIS, G., LIVADARAS, S., ARCA, B., ZABALOU, X. and SAVAKIS, C. (1995) Gene transfer into the Medfly, Ceratitis capitata, with a Drosophila hydei transposable element. Science 270:2002-2005.

MARGARITIS, L.H. (1985A) Comparative study of the eggshell of the fruit-flies Dacus oleae and Ceratitis capitata (Diptera: Tripeptidae). Can. J. Zool. 63(9):2194-2206.

MARGARITIS, L.H. (1985B) The eggshell of Drosophila melanogasterll. Covalent cross-linking of the chorion proteins involves endogenous hydrogen peroxide. Tissue Cel/17:553-559.

MARGARITIS, L.H. (1986) The eggshell of Drosophila melanogaster III. New staging characteristics and the fine structural analysis of choriogenesis. Can. J. Zool. 64:2152-2175.

MARGARITIS, L.H. and MAZZINI, M. (1998) Structure of the egg. In: Harrison FW and Locke M (Eds.), Microscopic Anatomy of Invertebrates, Wiley-Liss, New York, 11C, Insecta, pp 995-1037.

MARTINEZ-CRUZAD, O., SWIMMER, J.C.C., FENERJIAN, M.G. and KAFATOS, F.C. (1988) Evolution of the autosomal chorion locus in Drosophila. I. General organization of the locus and sequence comparisons of genes s15 and s19 in evolutionarily distant species. Genetics 119:663-667.

MINDRINOS, M.N., PETRI, W.H., GALANOPOULOS, V.K., LOMBARD, M.F. and MARGARITIS, L.H. (1980) Cross-linking of the Drosophila chorion involves a peroxidase. Wilhem Roux's Arch. 189:187-196.

MOUZAKI, D.G. and MARGARITIS, L.H. (1991a) Structure and morphogenesis of the eggshell and micropylar apparatus in the olive fly, Dacus oleae (Diptera: Tephritidae). J. Morphol. 209:39-52.

MOUZAKI, D.G. and MARGARITIS, L.H. (1991b) Choriogenesis in the Medfly Ceratitis capitata (Wiedermann) (Diptera: Tephritidae). Int. J Insect Morphol. Embryol. 29:51-68.

MOUZAKI, D.G. and MARGARITIS, L.H. (1994) The eggshell of the almond wasp 
Eurytoma amygdali (Hymanoptera: Eurytomidae)-1. Morphogenesis and fine structure of the eggshell layers. Tissue Cel/26:559-568.

OSHEIM, Y.N. and MILLER, JR.OL. (1983) Novel amplification and transcriptional activity of chorion c4 genes in Drosophila melanogaster follicle cells. Cell 33:543-553.

OSHEIM, Y.N., MILLER JR. OL. and BEYER, A.L. (1988) Visualization of Drosophila melanogaster chorion genes undergoing amplification. Mol. Cell. Biol. 8:2811-2821.

PARKS, S. and SPRADLING, A.C. (1987) Spatially regulated expression of chorion genes during Drosophila oogenesis. Genes Dev. 1:497-509.

REGIER, J.C. and KAFATOS, F.C. (1985) Molecular aspects of chorion formation. In: Gilbert LI, Kerkut GA (Eds.), Comprehensive Insect Biochemistry, Physiology and Pharmacology, Pergamon Press, Oxford and New York, 1:113-151.

SAMBROOK, J., FRITSCH, E.F. and MANIATIS, T. (1989) Molecular Cloning: A Laboratory Manual, Second Edition, Cold Spring Harbor Laboratory, Cold Spring Harbor, New York.

SOURMELI, S., KRAVARITI, L. and LECANIDOU, R. (2003) In vitro analysis of Bombyx moriearly chorion gene regulation: stage-specific expression involves interactions with C/EBP-like and GATA factors. Insect Biochem. Mol. Biol. 33:525-540.

SPRADLING, A.G. (1981) The organization and amplification of two chromosomal domains containing Drosophila chorion genes. Cel/27:193-201.

SPRADLING, A.G. and MAHOWALD, A.P. (1980) Amplification of genes for chorion proteins during oogenesis in Drosophila melanogaster. Proc. Natl. Acad. Sci. USA 77:1096-1100.

TROUGAKOS, I.P. and MARGARITIS, L.H. (1998A) The formation of the functional chorion structure of Drosophila virilis involves intercalation of the middle and late major chorion proteins into a scaffold formed by the early chorion proteins: a general model for chorion assembly in Drosophilidae. J. Struct. Biol. 123:97110.

TROUGAKOS, I.P. and MARGARITIS, L.H. (1998B) Immunolocalization of the temporally early secreted major structural chorion proteins Dvs38 and Dvs36 in the eggshell layers and regions of Drosophila virilis. J. Struct. Biol. 123:111-123.

TROUGAKOS, I.P. and MARGARITIS, L.H. (2002) Novel morphological and physiological aspects of insect eggs. In: Hilker M, Maners T, (Eds.), Chemoecology of insect eggs and egg deposition, Blackwell Wissenschaftsverlag, Berlin, Germany, pp 3-50.

VASQUEZ, M., ROTRIGUEZ, R. and ZURITA, M. (2002) A new peroxinectin-like gene preferentially expressed during oogenesis and early embryogenesis in Drosophila melanogaster. Dev. Genes Evol. 212:526-529.

VLACHOU, D., KONSOLAKI, M., TOLIAS, P.P., KAFATOS, F.C. and KOMITOPOULOU, K. (1997) The autosomal chorion locus of the medfly Ceratitis capitata. I. Conserved synteny, amplification and tissue specificity but sequence divergence and altered temporal regulation. Genetics 147(4):18291842.

ZHAO, X., SMART, C.T., LI, J. and CHRISTENSEN, B.M. (2001) Aedes aegypti peroxidase gene characterization and developmental expression. Insect Biochem. Mol. Biol. 31:481-490.

Received: November 2005

Reviewed by Referees: February 2006

Modified by Authors and Accepted for Publication: March 2006

Published Online: April 2006 